\title{
GEOQUÍMICA E GEOCRONOLOGIA PB-PB EM ZIRCÃO DA SUÍTE INTRUSIVA ÁGUA BRANCA, MUNICÍPIO DE PRESIDENTE FIGUEIREDO (AM): EVIDÊNCIAS DE COLISÃO NO PALEOPROTEROZÓICO DAAMAZÔNIA OCIDENTAL
}

\author{
CRISTÓVÃO DA SILVA VALÉRIO', VALMIR DA SILVA SOUZA², MOACIR JOSÉ BUENANO \\ MACAMBIRA $^{3}$ \& MARCO ANTONIO GALARZA ${ }^{4}$
}

\begin{abstract}
Resumo Os granitóides cálcio-alcalinos que ocorrem no Município de Presidente Figueiredo (AM) são representados por sienogranitos, monzogranitos e termos dioríticos porfiríticos, equigranulares, miloníticos e granofíricos da Suíte Intrusiva Água Branca. Essa unidade é caracterizada como uma série granítica que apresenta valores expandidos em $\mathrm{SiO}_{2}, \mathrm{Al}_{2} \mathrm{O}_{3}, \mathrm{Fe}_{2} \mathrm{O}_{3 \text { (total) }}$, $\mathrm{MgO}, \mathrm{CaO}$ e $\mathrm{Na}_{2} \mathrm{O}+\mathrm{K}_{2} \mathrm{O}$ e relativa homogeneidade na razão $\mathrm{Fe} / \mathrm{Mg}$, o que sugere magmas da Série Granodiorítica Cálcio-alcalina. Os elevados teores em $\mathrm{Ba}$, $\mathrm{Sr}$ e Rb/Zr e baixos valores em Nb, Rb, Ta, Zr, Zn, Y, K/Rb e ETRL da SIAB, aliados ao padrão de distribuição dos ETR e multielementos, indicam um ambiente sin-colisional com formação de arco magmático, geração de rochas cálcio-alcalinas meta a peraluminosas de médio a alto-K, do tipo I normal ou pouco fracionadas. A forte homogeneidade entre o padrão de distribuição de elementos compatíveis e incompatíveis das rochas da SIAB em relação às rochas de ambiente tipicamente sin- e pós-colisional, contribui com a proposta de um regime colisional envolvendo os processos finais de colagem, subducção de uma paleoplaca oceânica contra o protocráton Amazônico (Província Amazônia Central), subseqüente construção da Província Ventuari-Tapajós, associados ao magmatismo Água Branca, gerado há ca. 1,89 Ga. As avaliações geológicas, geoquímicas e geocronológicas sugerem uma correlação estratigráfica entre a Suíte Intrusiva Água Branca, na área de estudo e a Suíte Intrusiva Tropas (Parauari), na Província Aurífera Tapajós, porção sul da Província Ventuari-Tapajós.
\end{abstract}

Palavras-chave: granitóides cálcio-alcalinos, Paleoproterozóico, geocronologia de zircão, Escudo das Guianas.

\begin{abstract}
GEOCHEMISTRY AND Pb-EVAPORATION ZIRCON GEOCHRONOLOGY OF THE AGUA BRANCA INTRUSIVE SUITE, PRESIDENTE FIGUEIREDO DISTRICT: EVIDENCE OF THE PALEOPROTEROZOIC COLLISION IN WESTERN AMAZONIAN The calc-alkaline granitoids of the President Figueiredo district, Amazonas State, Brazil, are represented by syenogranites, monzogranites and diorites of the Água Branca Intrusive Suite that display porphyry, equigranular, mylonitic and granophiric textural variation. This unit is characterized as a granitic series that presents expanded values of $\mathrm{SiO}_{2}, \mathrm{Al}_{2} \mathrm{O}_{3}$, $\mathrm{Fe}_{2} \mathrm{O}_{3 \text { (total) }}, \mathrm{MgO}, \mathrm{CaO}$ and $\mathrm{Na}_{2} \mathrm{O}+\mathrm{K}_{2} \mathrm{O}$, and relative homogeneity in $\mathrm{Fe} / \mathrm{Mg}$ ratio, suggesting an origin from magmas of the calcalkaline granodioritic series. The high values in $\mathrm{Ba}, \mathrm{Sr}$ and $\mathrm{Rb} / \mathrm{Zr}$, and low values in $\mathrm{Nb}, \mathrm{Rb}, \mathrm{Ta}, \mathrm{Zr}, \mathrm{Zn}, \mathrm{Y}, \mathrm{K} / \mathrm{Rb}$ and LREE of Água Branca Intrusive Suite, added to the REE and multi-elements distribution pattern, indicate a sin-collisional tectonic setting with formation of magmatic arc and generation of rocks with metaluminous to peraluminous, calc-alkaline from medium to high-K and I normal type or weakly fractionated geochemical characteristics. The strong homogeneity between compatible and incompatible elements distribution of the Água Branca Intrusive Suite rocks and typically sin- to post-collision rocks, contributes with a proposal of a collision regime involving the final subduction-related collage processes, of the oceanic paleoplate under the Amazonian protocráton (Central Amazonian Province), and subsequent construction of the Ventuari-Tapajós Province, associated to the Água Branca magmatism, ca. $1.89 \mathrm{Ga}$. The geological, geochemical and geochronological data suggest stratigraphic correlation between Água Branca Intrusive Suite and (Parauari) Tropas Intrusive Suite from Tapajós Gold Province, southern portion of the Ventuari-Tapajós Province.
\end{abstract}

Keywords: calc-alkaline granitoids, Paleoproterozoic, zircon geochronology, Guiana Shield.

INTRODUÇÃO O Município de Presidente Figueiredo (AM) está localizado no extremo sul do Escudo das Guianas, próximo à borda norte da Bacia do Amazonas, inserido no contexto geológico da porção central da Província da Ventuari-Tapajós. Na região, ocorrem rochas cálcio-alcalinas de composição granodiorítica a quartzo-diorítica que integram o embasamento granito-gnáissico gerado a partir de processos de diferenciação mantélica em um arco magmático entre 1,95 e 1,88 Ga e que se mostra associado a granitóides de composição similar e de caráter sin- a pós-tectônico (p.ex. Tassinari \& Macambira 2004).

Os granitóides cálcio-alcalinos do Município de Presidente Figueiredo e entorno são representados pela Suíte Intrusiva Água Branca (SIAB, Fig. 1). Esta suíte, assim designada por Oliveira et al. (1996a), é caracterizada como uma série granítica expandida formada por termos que variam desde os predominantes monzogranitos e granodioritos porfiríticos até dioritos, os quais se revelaram metaluminosos a fracamente peraluminosos de alto-K e temporalmente associados à Suíte Igarapé Azul $(1,89-1,90 \mathrm{Ga})$, porém, com marcantes diferenças geoquímicas (Oliveira et al. 1996b, CPRM 2000, Almeida et al. 2002 e Almeida \& Macambira 2003). Esses autores confirmaram o processo de geração por cristalização fracionada (Oliveira et al. 1996b) que envolveu, sobretudo, a participação de plagioclásio, anfibólio e óxidos de Fe-Ti. Alertaram ainda para atuação localizada de assimilação e contaminação da rocha encaixante.

A SIAB tem sido freqüentemente relacionada ao vulcanismo Iricoumé e interpretada como produto gerado a partir de fontes mantélicas em ambiente colisional com relativa contribuição crustal (CPRM 2000, Reis et al. 2003). Desse modo, Fraga \& Reis (2002) propuseram distinguir o vulcano-plutonismo Iricoumé-Água Branca do evento cálcio-alcalino Orocaima $(\sim 1,96$ Ga, Reis et al. 2000).

1 - Programa de Pós-Graduação em Geociências (PPGEO), Departamento de Geociências (DEGEO), Universidade Federal do Amazonas (UFAM), valerio_ cs@hotmail.com, CEP 69077-000, Manaus/AM.

2 - Departamento de Geociências (DEGEO), Universidade Federal do Amazonas (UFAM), valmirsouza@ufam.edu.br, CEP 69077-000, Manaus/AM.

3 - Laboratório de Geologia Isotópica, Centro de Geociências, Universidade Federal do Pará, moamac@ufpa.br, Caixa Postal 8608, 66075-100 Belém/PA.

4 - Laboratório de Geologia Isotópica, Centro de Geociências, Universidade Federal do Pará, antogt@ufpa.br, Caixa Postal 8608, 66075-100 Belém/PA. 


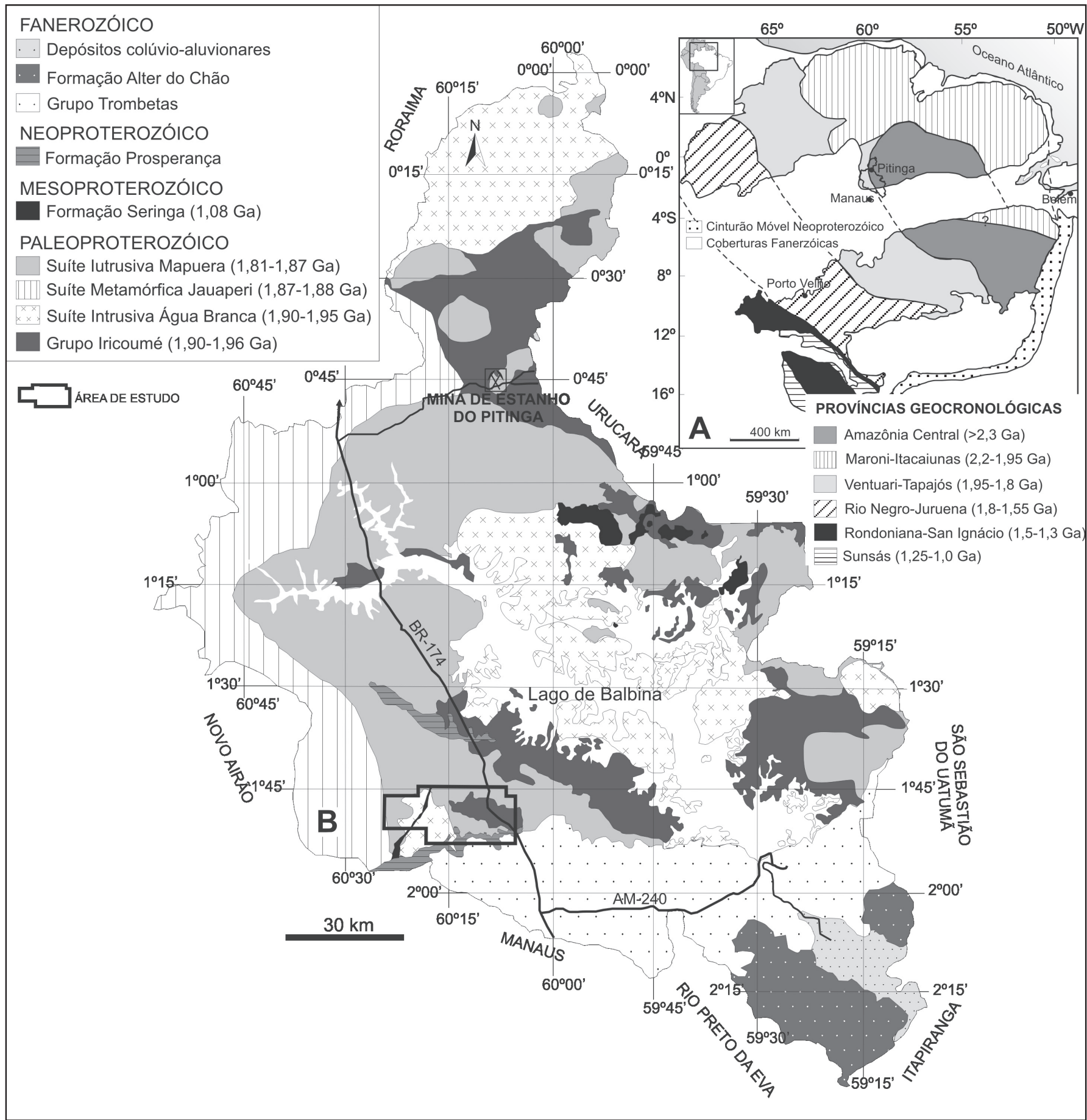

Figura 1. (A) Proposta de compartimentação geocronológica para Cráton Amazônico (Tassinari \& Macambira 2004). (B) Mapa geológico simplificado do Município de Presidente Figueiredo, indicando o Estado de Roraima e municípios adjacentes (CPRM 2002).

Este artigo apresenta o arranjo geológico proposto para os granitóides cálcio-alcalinos Água Branca na porção sudoeste do Município de Presidente Figueiredo, nordeste do Estado do Amazonas, região limítrofe entre as rochas sedimentares paleozóicas da Bacia do Amazonas e o embasamento granítico pertencendo ao Escudo das Guianas.

As revisões dos dados sobre a geocronologia e tectono-geoquímica regionais (Tab. 1), acompanhadas das novas informações geoquímicas e isotópicas $\mathrm{Pb}-\mathrm{Pb}$ apresentadas neste artigo, auxiliam nas discussões sobre séries magmáticas, tipologia de granitóides, ambiente e evolução geológica da Província Ventuari-Tapajós do Cráton Amazônico.
GEOLOGIA E PETROGRAFIA A SIAB mostra-se segmentada por lineamentos NW-SE com fortes inflexões para N, que controlam alguns trechos do Rio Pardo e é cortada por diques de biotita microsienogranito, diabásio e olivina gabro. No extremo oeste da área de ocorrência da unidade, os lineamentos mostram-se arranjados de forma circular, limitando espessos platôs lateríticos (Fig. 2). Essa unidade é representada pelos tipos diorito, biotita-quartzo diorito, biotita-hornblenda granito protomilonítico, biotita granitos porfirítico e equigranular, biotita granito granofírico e biotita granito milonítico.

$\mathrm{O}$ diorito e o biotita-quartzo diorito exibem textura ineqüigranular grossa à média e microtextura sub-ofítica a intergra- 
Tabela 1. Informações geocronológicas obtidas em cristais de zircão de granitóides calcialcalinos tipo I da porção central do cráton Amazônico.

\begin{tabular}{lllll}
\hline Estratigrafia & Região & Método & Idade (Ma) & Referência \\
\hline Granitóides tipo I & & & & \\
Granito Jardim do Ouro & Vila Riozinho, Tapajós (PA) & Evaporação de Pb & $1880 \pm 3$ & Lamarão et al. (2002) \\
Granito São Jorge Jovem & Vila Riozinho, Tapajós (PA) & Evaporação de Pb & $1891 \pm 3$ & Lamarão et al. (2002) \\
Suíte Intrusiva Água Branca & SE Roraima (RR) & U-Pb ID-TIMS & $1891 \pm 7$ & Santos, in Reis et al. 2003 \\
Suite Intrusive Parauari & Tapajós (PA) & U-Pb ID-TIMS & $1897 \pm 6$ & Santos et al. (2000) \\
Suíte Intrusiva Tropas & Tapajós (PA) & U-Pb ID-TIMS & $1897 \pm 2$ & Santos et al. (2004) \\
Suíte Intrusiva Pedra Pintada & N Roraima (RR) & U-Pb SHRIMP & $1958 \pm 11$ & Santos (1999) \\
Granito São Jorge Antigo & Vila Riozinho, Tapajós (PA) & Evaporação de Pb & $1981 \pm 2$ & Lamarão et al. (2002) \\
\hline
\end{tabular}

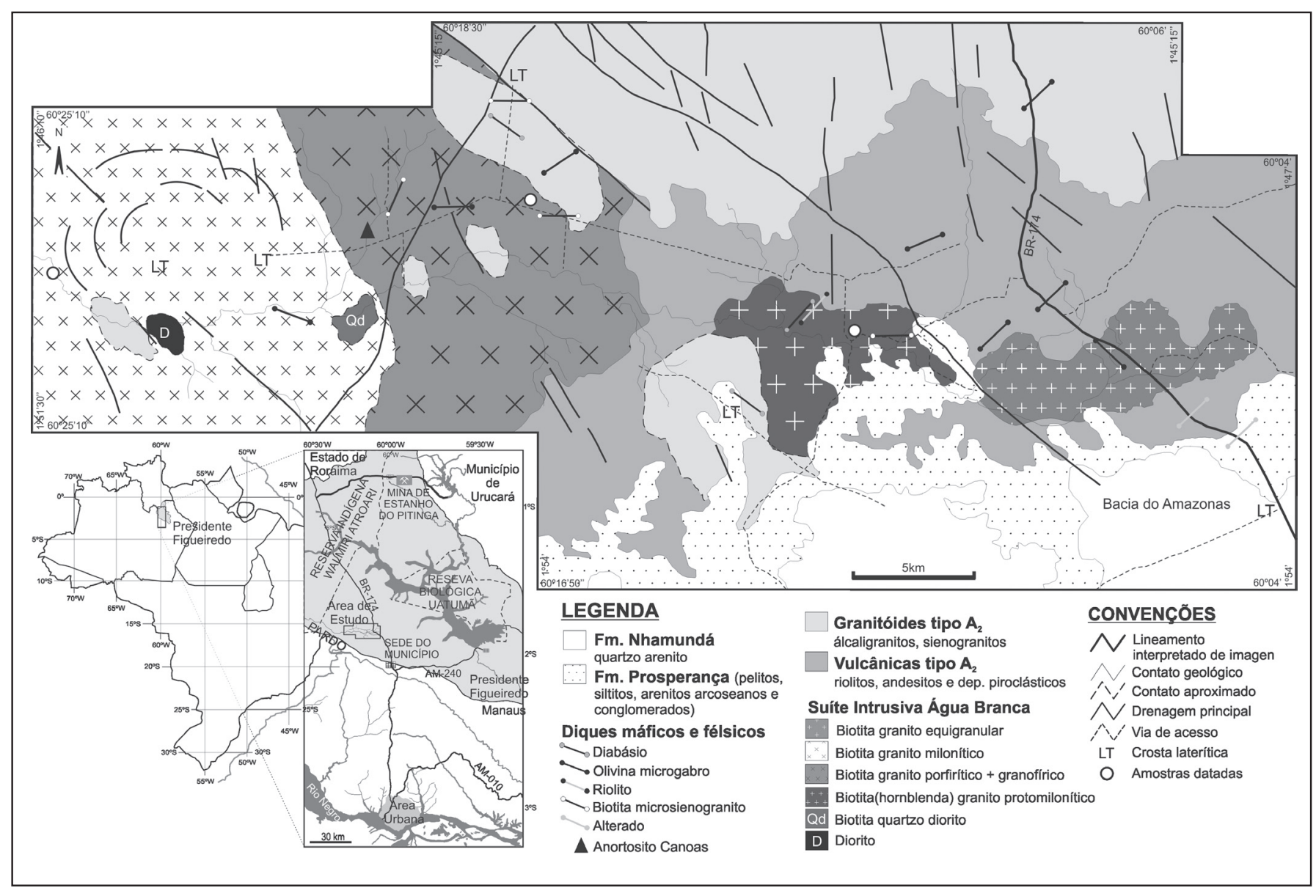

Figura 2. Mapa geológico do extremo sul do Escudo das Guianas, sudoeste do Município de Presidente Figueiredo (área de estudo). A figura destaca ainda a distribuição areal e as variações petrográficas da Suite Intrusiva Água Branca, além dos principais lineamentos interpretados a partir dos produtos de sensoriamento remoto LANDSAT TM, JERS e MDT.

nular, com uma paragênese mineral composta por oligoclásio, anfibólio, biotita, quartzo, microclínio, augita, além de minerais acessórios (apatita e minerais opacos) e hidrotermais (clorita e epidoto) (Fig. 3A).

$\mathrm{O}$ biotita granito pórfiro exibe estruturas ígneas bem preservadas (Fig. 3B), enclaves dioríticos subarredondados (Fig. 3B), fenocristais de feldspatos zonados de até $5 \mathrm{~cm}$ e matriz de granulação média a grossa (Fig. 3C). A paragênese mineral é representada por quartzo, cristais e fenocristais de microclínio, oligoclásio normalmente com zonamento oscilatório, biotita, minerais acessórios (zircão, apatita, opacos e cristais euédricos de titanita) e minerais da série do epidoto, clorita e óxidos de ferro hidrotermais (Fig. 3D). O biotita granito equigranular é um exemplo de variação textural da fácies porfirítica, ocorrendo de modo disseminado em meio desta fácies e em toda porção leste da SIAB. Outro tipo petrográfico, comumente associado ao granito porfirítico, exibe marcantes intercrescimentos granofíricos vermiculares e/ou em chama (Fig. 3E). Tais feições são origi- 
nadas pela cristalização simultânea do quartzo e K-feldspato a partir de misturas eutéticas ricas em voláteis, em condições epizonais e comumente associadas aos processos tardi/pós-magmáticos (Hibbard 1979 e 1987, Hughes 1982).

Os termos miloníticos demonstram aspecto textural porfiróide, matriz de granulação média, proeminente foliação NW-SE/ vertical e bandamento incipiente. $\mathrm{O}$ arranjo textural milonítico a protomilonítico é ressaltado por porfiroclastos de feldspato rodeados por uma matriz quartzo-feldspática de granulação média produto de recristalização incipiente (Fig. 3F).

No diagrama modal QAP (Fig. 4), as rochas da SIAB estão posicionadas predominantemente no campo dos monzogranitos,
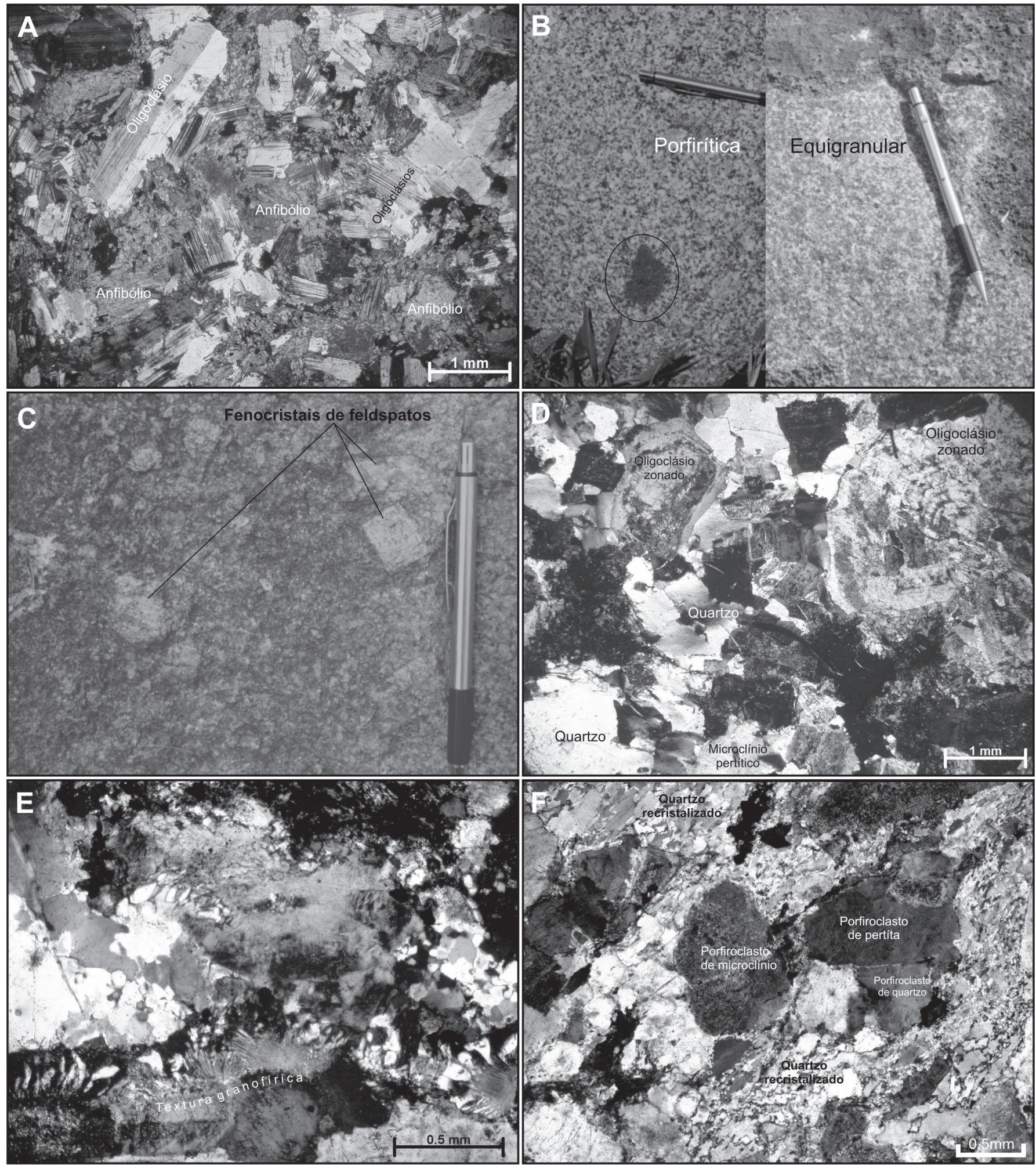

Figura 3. Aspectos de campo, meso- e microscópico dos granitóides Água Branca. Arranjo microtextural do quartzo diorito (A) Aspecto mesotextural das fácies porfirítica e equigranular do biotita granito com destaque, no circulo, a um enclave diorítico (B). Detalhe de fenocristais de oligoclásio zonados na fácies porfirítica (C), biotita granito pórfiro (D), biotita granito granofirico (E) e granito milonítico $(F)$. 


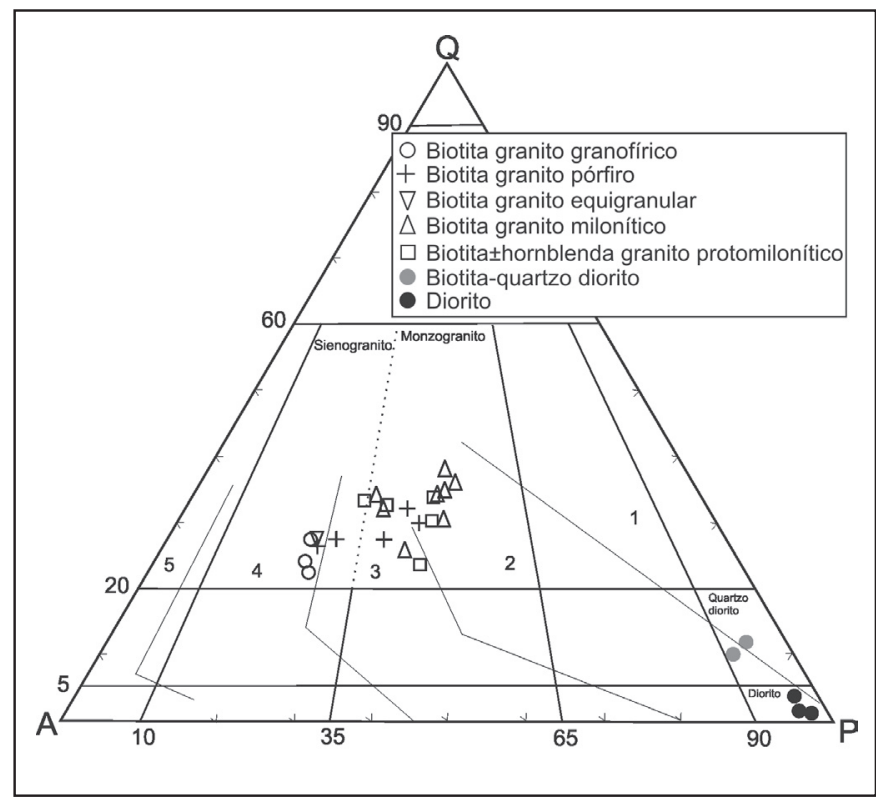

Figura 4. Diagrama de composição modal Q-A-P para os granitóides investigados (Streckeisen 1976). Séries graniticas de acordo com Bowden et al. (1984): 1) cálcio-alcalina-tonalítica; 2) cálcio-alcalina-granodiorítica; 3) subalcalina-monzonítica; 4) alumino-potássica; 5) alcalina-sódica.v

enquanto os granófiros e o biotita granito eqüigranular apresentam composição modal sienogranítica e os dioritos composições quartzo-diorítica e dioríticas. Segundo a classificação de séries graníticas, essas rochas estão distribuídas nas séries granodiorítica calcialcalina e monzonítica subalcalina, enquanto o granófiro se posiciona no campo das rochas alumino-potássicas.

PROCEDIMENTOS ANALÍTICOS As análises geoquímicas em rocha total foram realizadas no laboratório ACME, em Vancouver, Canadá. Os elementos maiores $\mathrm{SiO}_{2}, \mathrm{TiO}_{2}, \mathrm{Al}_{2} \mathrm{O}_{3}$, $\mathrm{Fe}_{2} \mathrm{O}_{3 \text { total }}, \mathrm{MnO}, \mathrm{MgO}, \mathrm{CaO}, \mathrm{Na}_{2} \mathrm{O}, \mathrm{K}_{2} \mathrm{O}$ e $\mathrm{P}_{2} \mathrm{O}_{5}$ foram determinados por Inductively Coupled Plasma Atomic Emission Spectrometry (ICP-AES), e os traços Ba, Rb, Cs, Ga, Hf, Nb, Y, Sr, Ta, Th, U, V, W, Zr, Sc, Pb, Zn e Ni, juntamente com os Elementos Terras Raras (ETR), foram determinados por Inductively Coupled Plasma Atomic Mass Spectrometry (ICP-AMS).

As informações geocronológicas foram obtidas pelo método $\mathrm{Pb}-\mathrm{Pb}$ por evaporação de monocristais de zircão em duplo filamento (Köber 1987), realizado no Laboratório de Geologia Isotópica (PARÁ-ISO), Centro de Geociências da Universidade Federal do Pará (CG/UFPA). Esse método consiste na separação e seleção de cristais de zircão, análise desses cristais no espectrômetro FINNIGAN MAT 262 e tratamento dos dados isotópicos obtidos.

A técnica analítica utiliza um filamento de evaporação com o zircão posicionado em frente a um filamento de ionização. O filamento de evaporação é aquecido gradativamente a partir $1450^{\circ} \mathrm{C}$, com duração de cinco minutos cada etapa. Nessas etapas, ocorre a liberação do $\mathrm{Pb}$ do retículo cristalino do zircão, o qual se deposita no filamento de ionização. Em seguida, o filamento de ionização, mantido em temperatura ambiente, é aquecido a uma temperatura em torno de $1050^{\circ} \mathrm{C}$.

As intensidades das emissões dos diferentes isótopos de $\mathrm{Pb}$ são medidas em baixa intensidade de sinal, com monocoletor (um contador de íons), em cinco varreduras das massas 206, 207, 208, 206, 207 e 204. Cada conjunto de cinco varreduras define um bloco obtido no contador de íons, que fornece 18 ra- zões ${ }^{207} \mathrm{~Pb} /{ }^{206} \mathrm{~Pb}$. Em seguida, a partir das médias dessas razões definiu-se uma idade para cada etapa de evaporação. A cada uma destas etapas são obtidos até cinco blocos de dados, cuja média das razões ${ }^{207} \mathrm{~Pb} / 206 \mathrm{~Pb}$ define uma idade correspondente para cada etapa. Esses dados são representados em um diagrama Idade (Ma) versus Etapas de Evaporação. Das idades obtidas nas diferentes etapas de evaporação, em geral, àquelas correspondentes as obtidas em temperaturas mais altas são utilizadas, pois nesse caso, o $\mathrm{Pb}$ analisado, teoricamente, é proveniente das porções mais retentivas do cristal de zircão e, portanto, mais representativas da idade de cristalização do mineral. Os resultados são apresentados com 2 de desvio padrão e as correções do $\mathrm{Pb}$ comum inicial são realizadas mediante uso do modelo de evolução do Pb em estágio duplo proposto por Stacey \& Kramers (1975), utilizando a razão ${ }^{204} \mathrm{~Pb} /{ }^{206} \mathrm{~Pb}$.

Os dados obtidos são tratados estatisticamente segundo critérios metodológicos estabelecidos por Gaudette et al. (1998), dentre os quais se excluem blocos com razões isotópicas ${ }^{204} \mathrm{~Pb} /$ ${ }^{206} \mathrm{~Pb}>0,0004$ com desvios padrões superiores a 2 em relação à média das idades dos cristais de zircão, e blocos, etapas de evaporação e/ou cristais que apresentarem idades discordantes da média das idades obtidas nas temperaturas mais altas da maioria das análises.

GEOQUÍMICA As rochas investigadas revelam comportamento geoquímico análogo, o que permitiu individualizá-las em um único grupo geoquímico. As diferentes fácies graníticas da SIAB apresentam valores expandidos em $\mathrm{SiO}_{2}$ entre 65 e $72 \%$ (Tab. 2), índice de saturação em alumina posicionado na interface das rochas meta- e peraluminosa, ISA entre 0,94 e 1,06 e assinatura cálcio-alcalina (subalcalina) de alto-K (Fig. 5A e B). Já a fácies diorítica apresenta teores normais em $\mathrm{SiO}_{2}(54 \%)$, $\mathrm{TiO}_{2}(0,8 \%), \mathrm{Fe}_{2} \mathrm{O}_{3 \text { total }}(10,42 \%)$ e $\mathrm{CaO}(7,6 \%)$, ISA francamente metaluminoso $(0,8)$ e caráter cálcio-alcalino de médio-K.

Em termos de elementos traços, os granitóides Água Branca revelam altos valores em $\mathrm{Ba}$ e $\mathrm{Sr}$, baixos teores em $\mathrm{Zn}, \mathrm{Nb}, \mathrm{Rb}$, Ta, Zr e Y e variações em Th (9 a 23 ppm) e U (1 a 11 ppm). A relação $\mathrm{La}+\mathrm{Ce}$, apresenta valores altos, cerca de $80-130$ vezes maiores que os dos condritos. No diagrama de distribuição dos ETR (Fig. 6), as rochas dessa unidade exibem fraca anomalia negativa em $\mathrm{Eu}$, da ordem $\left[\mathrm{Eu} / \mathrm{Eu}^{*}\right]_{\mathrm{N}}=0,60-0,88$, moderado a forte enriquecimento dos ETR leves $\left[(\mathrm{La} / \mathrm{Sm})_{\mathrm{N}}=5,00-7,63\right]$ em relação aos pesados $\left[(\mathrm{Gd} / \mathrm{Yb})_{\mathrm{N}}=1,22-1,77\right]$, o que indica um padrão de fracionamento moderado a forte $\left[(\mathrm{La} / \mathrm{Yb})_{\mathrm{N}}=\right.$ 12,6-23,2]. O padrão de distribuição dos elementos compatíveis e incompatíveis revela anomalias positivas em Rb, U, La e Tb e anomalias negativas em $\mathrm{Cs}, \mathrm{Ba}$, Th, Nb, Ti e Y (Fig. 6).

$\mathrm{O}$ diorito também mostra altos valores em $\mathrm{Ba}(716 \mathrm{ppm})$ e $\mathrm{Sr}(615 \mathrm{ppm})$ e baixos valores em Zn (54 ppm), Rb (56 ppm), $\mathrm{Nb}$ (4,2 ppm), Zr (50 ppm) e Y (21 ppm). Em relação aos ETR, o diorito manifesta baixos valores de $\mathrm{La}+\mathrm{Ce}$, em torno de 17 vezes maiores que os do condrito e valores de $\mathrm{Yb}+\mathrm{Lu}$ menores que os dos condritos. O padrão de distribuição dos ETR exibe formato convexo com fraca anomalia positiva em $\mathrm{Eu}$, da ordem $\left[\mathrm{Eu} / \mathrm{Eu}^{*}\right]_{\mathrm{N}}=1,4$, moderado enriquecimento dos ETR leves, de razão $[\mathrm{La} / \mathrm{Sm}]_{\mathrm{N}}=3,3$, em relação aos pesados, da ordem de $[\mathrm{Gd} /$ $\mathrm{Yb}]_{\mathrm{N}}=1,7$, indicativo de um moderado a fraco fracionamento, da ordem de $(\mathrm{La} / \mathrm{Yb})_{\mathrm{N}} \sim 8$ (Fig. 6). No diagrama multielementar, o diorito revela picos em $\mathrm{Ba}, \mathrm{K}, \mathrm{La}, \mathrm{Sr}, \mathrm{Sm}$ e Tb, e depressões em Cs, Th, Ta, Ce, Zr, Ti e Y (Fig. 6).

Ambiente tectônico e tipologia de granitos Os elevados teores em $\mathrm{Ba}, \mathrm{Sr}$ e Rb/Zr e baixos valores em $\mathrm{Nb}, \mathrm{Rb}, \mathrm{Ta}, \mathrm{Zr}, \mathrm{Zn}, \mathrm{Y}$, $\mathrm{K} / \mathrm{Rb}$ e ETRL da SIAB (Valério et al. 2006a) são observados em rochas cálcio-alcalinas originadas em ambientes sin-colisionais (Pearce et al. 1984, Harris et al. 1986). O diagrama discriminan- 
Tabela 2. Composição química de amostras da Suite Intrusiva Água Branca.

\begin{tabular}{|c|c|c|c|c|c|c|c|c|c|c|c|c|c|c|}
\hline \multirow{2}{*}{$\begin{array}{l}\text { Litotipo } \\
\text { Amostra }\end{array}$} & \multicolumn{6}{|c|}{ biotita granito pórfiro } & \multicolumn{4}{|c|}{$\begin{array}{l}\text { biotita granito } \\
\text { granofírico }\end{array}$} & \multirow{2}{*}{$\begin{array}{l}\text { biotita } \\
\text { granito } \\
\text { equigranular }\end{array}$} & \multirow{2}{*}{$\begin{array}{l}\begin{array}{l}\text { biotita } \\
\text { granito } \\
\text { milonítico }\end{array} \\
\text { C3504 }\end{array}$} & \multirow{2}{*}{$\begin{array}{l}\begin{array}{l}\text { biotita } \pm \\
\text { hornblenda } \\
\text { granito } \\
\text { nrotomilonítico }\end{array} \\
\text { C6304 }\end{array}$} & \multirow{2}{*}{$\begin{array}{l}\text { diorito } \\
\text { C2804 }\end{array}$} \\
\hline & $\mathrm{C} 0504 \mathrm{~A}$ & C2104A & C2104B & C5004A & C5004B & C6504 & $\mathrm{C} 0404 \mathrm{~A}$ & C5104A & C5104B & REC5104B & & & & \\
\hline $\mathrm{SiO}_{2}(\%)$ & 72,59 & 68,63 & 68,91 & 70,43 & 70,46 & 66,92 & 71,2 & 66,91 & 66,91 & 67,28 & 66,9 & 72,33 & 65,13 & 54,15 \\
\hline $\mathrm{TiO}_{2}$ & 0,2 & 0,34 & 0,34 & 0,28 & 0,29 & 0,45 & 0,21 & 0,32 & 0,34 & 0,34 & 0,39 & 0,23 & 0,41 & 0,8 \\
\hline $\mathrm{Al}_{2} \mathrm{O}_{3}$ & 14,13 & 15,4 & 15,18 & 14,98 & 14,97 & 15,82 & 14,97 & 16,5 & 16,48 & 16,04 & 16,76 & 14,7 & 15,83 & 16,88 \\
\hline $\mathrm{Fe}_{2} \mathrm{O}_{3}$ & 1,73 & 2,85 & 2,84 & 2,26 & 2,25 & 3,48 & 1,78 & 2,92 & 2,91 & 3,05 & 3,04 & 2,06 & 3,95 & 10,42 \\
\hline $\mathrm{MnO}$ & 0,03 & 0,05 & 0,06 & 0,05 & 0,05 & 0,06 & 0,05 & 0,07 & 0,07 & 0,08 & 0,06 & 0,07 & 0,07 & 0,16 \\
\hline $\mathrm{MgO}$ & 0,31 & 1,09 & 1,13 & 0,84 & 0,82 & 1,35 & 0,43 & 1,19 & 1,18 & 1,28 & 1 & 0,5 & 1,74 & 4,06 \\
\hline $\mathrm{CaO}$ & 1,3 & 2,65 & 2,66 & 2,24 & 2,21 & 2,95 & 1,86 & 2,52 & 2,58 & 2,62 & 2,78 & 1,62 & 3,51 & 7,6 \\
\hline $\mathrm{Na}_{2} \mathrm{O}$ & 3,74 & 4,04 & 3,96 & 4,04 & 4 & 3,97 & 4,11 & 4,72 & 4,68 & 4,48 & 4,66 & 4,03 & 3,74 & 3,37 \\
\hline $\mathrm{K}_{2} \mathrm{O}$ & 4,68 & 3,84 & 3,73 & 4,06 & 4,02 & 3,79 & 4,12 & 3,75 & 3,63 & 3,81 & 3,43 & 4,02 & 4 & 1,55 \\
\hline $\mathrm{P}_{2} \mathrm{O}_{5}$ & 0,06 & 0,13 & 0,12 & 0,09 & 0,09 & 0,16 & 0,08 & 0,12 & 0,14 & 0,13 & 0,14 & 0,08 & 0,16 & 0,27 \\
\hline $\mathrm{PF}$ & 1 & 0,8 & 0,9 & 0,6 & 0,7 & 0,7 & 0,9 & 0,8 & 0,9 & 0,7 & 0,6 & 0,2 & 1,3 & 0,6 \\
\hline Total & 99,81 & 99,81 & 99,84 & 99,98 & 99,85 & 99,65 & 99,72 & 99,82 & 99,82 & 99,82 & 99,76 & 99,84 & 99,85 & 99,87 \\
\hline Mo (ppm) & 0,1 & 0,2 & 0,4 & 0,3 & 0,2 & 0,4 & 0,1 & 1,2 & 1,2 & 1,3 & 0,2 & 0,2 & 0,5 & 0,3 \\
\hline $\mathrm{Cu}$ & 12,3 & 5,7 & 6,2 & 7,8 & 7,5 & 18 & 8,2 & 4,3 & 5,2 & 5 & 14 & 11,9 & 4,5 & 26,1 \\
\hline $\mathrm{Pb}$ & 12,8 & 5,1 & 4,4 & 10,1 & 8,8 & 5,1 & 4,6 & 5,6 & 5,7 & 5,5 & 2,6 & 2,1 & 5,4 & 1 \\
\hline $\mathrm{Zn}$ & 33 & 40 & 48 & 41 & 40 & 57 & 33 & 48 & 51 & 51 & 56 & 47 & 28 & 54 \\
\hline $\mathrm{Ni}$ & 0,8 & 9,7 & 10,7 & 7,8 & 7,4 & 12,7 & 1,5 & 8,5 & 8,3 & 8,7 & 4,9 & 2,1 & 11,4 & 19,6 \\
\hline $\mathrm{Ba}$ & 1245,9 & 1090,9 & 888,8 & 915,5 & 959,6 & 1255,1 & 984,6 & 1034,6 & 1023,9 & 1013,9 & 1295,9 & 1199,1 & 940,3 & 716,4 \\
\hline $\mathrm{Ga}$ & 18,2 & 18,3 & 18,8 & 18,6 & 19,8 & 19,1 & 19,4 & 19,2 & 18,2 & 18,1 & 19,9 & 16,5 & 19,2 & 21,5 \\
\hline Hf & 5,3 & 4,4 & 3,9 & 4,1 & 4,5 & 4,4 & 4,2 & 3,9 & 3,9 & 3,9 & 4,8 & 4,5 & 4,1 & 1,5 \\
\hline $\mathrm{Nb}$ & 13,9 & 8,7 & 9,2 & 9,3 & 10,1 & 9,9 & 11,2 & 7 & 8,1 & 7,6 & 8,7 & 6,1 & 7,2 & 4,2 \\
\hline $\mathrm{Rb}$ & 171,6 & 121,4 & 132,1 & 143,3 & 147,1 & 123,7 & 152,7 & 150,1 & 139,6 & 140,1 & 94,4 & 88,8 & 142,5 & 56,4 \\
\hline $\mathrm{Sr}$ & 295,3 & 633,7 & 632,8 & 448,5 & 469,3 & 649 & 493,1 & 625,5 & 608,1 & 594,9 & 672,9 & 419,6 & 657,6 & 615,5 \\
\hline $\mathrm{Ta}$ & 1 & 0,7 & 0,8 & 1 & 1,1 & 0,8 & 1,1 & 0,5 & 0,7 & 0,7 & 0,8 & 0,3 & 0,6 & 0,2 \\
\hline Th & 12 & 6,7 & 19,4 & 23,1 & 20,9 & 14,5 & 14 & 8,8 & 12,1 & 8,3 & 10,7 & 10,2 & 15,4 & 1,9 \\
\hline U & 3,9 & 2,5 & 3,4 & 11,2 & 10,8 & 4,5 & 3,9 & 3,1 & 4,2 & 2,7 & 2,8 & 1,1 & 4,9 & 0,6 \\
\hline V & 13 & 42 & 43 & 34 & 34 & 55 & 23 & 41 & 40 & 41 & 44 & 17 & 72 & 226 \\
\hline W & 0,6 & 0,3 & 0,2 & 0,5 & 0,6 & 0,3 & 0,2 & 1 & 0,7 & 1 & 0,2 & 0,1 & 0,6 & 0,3 \\
\hline $\mathrm{Zr}$ & 181,9 & 152,4 & 143,6 & 125 & 140,5 & 148,3 & 140,5 & 150,8 & 141,3 & 132 & 179,5 & 160,8 & 140,2 & 49,7 \\
\hline Y & 21,1 & 12,9 & 14,9 & 16,3 & 17,7 & 21,8 & 15,2 & 14,8 & 17,4 & 15,5 & 18,7 & 15,5 & 17,5 & 21,5 \\
\hline $\mathrm{La}(\mathrm{ppm})$ & 42,5 & 16,1 & 36,3 & 40,4 & 44,1 & 44,2 & 29,8 & 36,2 & 35,8 & 40 & 34,8 & 33,9 & 35,4 & 23,3 \\
\hline $\mathrm{Ce}$ & 83,2 & 82,3 & 73,2 & 75,2 & 81,7 & 90,5 & 59,9 & 68,5 & 71,7 & 75,3 & 72,1 & 67,5 & 72 & 49 \\
\hline $\operatorname{Pr}$ & 8,51 & 7,71 & 7,64 & 7,35 & 7,92 & 9,63 & 6,23 & 7 & 7,79 & 7,63 & 7,79 & 6,97 & 7,79 & 5,57 \\
\hline $\mathrm{Nd}$ & 29,8 & 25,6 & 27,7 & 25,4 & 27,7 & 36,5 & 22,8 & 25,5 & 29,5 & 27,1 & 29,1 & 24,6 & 29,5 & 22,4 \\
\hline $\mathrm{Sm}$ & 4,9 & 3,8 & 4,3 & 3,7 & 3,9 & 5,6 & 3,7 & 3,9 & 4,6 & 4 & 4,8 & 3,9 & 4,3 & 4,4 \\
\hline $\mathrm{Eu}$ & 0,8 & 0,83 & 0,88 & 0,84 & 0,78 & 1,15 & 0,73 & 0,93 & 0,99 & 0,9 & 1,11 & 0,76 & 0,95 & 1,95 \\
\hline Gd & 3,43 & 2,46 & 3,04 & 2,69 & 2,97 & 3,86 & 2,42 & 2,7 & 3,19 & 2,69 & 3,29 & 2,87 & 2,9 & 4,06 \\
\hline $\mathrm{Tb}$ & 0,62 & 0,35 & 0,42 & 0,42 & 0,45 & 0,65 & 0,41 & 0,45 & 0,49 & 0,43 & 0,54 & 0,45 & 0,48 & 0,63 \\
\hline Dy & 3,3 & 1,94 & 2,4 & 2,22 & 2,28 & 3,2 & 2,25 & 2,15 & 2,72 & 2,27 & 2,83 & 2,64 & 2,52 & 3,58 \\
\hline Ho & 0,7 & 0,39 & 0,47 & 0,48 & 0,52 & 0,64 & 0,47 & 0,46 & 0,52 & 0,47 & 0,59 & 0,49 & 0,51 & 0,73 \\
\hline $\mathrm{Er}$ & 2,02 & 1,16 & 1,31 & 1,38 & 1,48 & 1,84 & 1,39 & 1,34 & 1,57 & 1,41 & 1,6 & 1,38 & 1,48 & 2,06 \\
\hline $\operatorname{Tm}$ & 0,33 & 0,2 & 0,22 & 0,24 & 0,27 & 0,29 & 0,23 & 0,2 & 0,23 & 0,23 & 0,25 & 0,21 & 0,25 & 0,29 \\
\hline $\mathrm{Yb}$ & 2,24 & 1,34 & 1,54 & 1,55 & 1,79 & 1,76 & 1,6 & 1,44 & 1,71 & 1,55 & 1,7 & 1,35 & 1,67 & 1,96 \\
\hline $\mathrm{Lu}$ & 0,36 & 0,23 & 0,25 & 0,28 & 0,28 & 0,29 & 0,3 & 0,22 & 0,26 & 0,23 & 0,29 & 0,2 & 0,27 & 0,29 \\
\hline ISA & 1,45 & 1,46 & 1,47 & 1,45 & 1,46 & 1,48 & 1,48 & 1,50 & 1,51 & 1,47 & 1,54 & 1,52 & 1,41 & 1,35 \\
\hline $\mathrm{K}_{2} \mathrm{O} / \mathrm{Na}_{2} \mathrm{O}$ & 1,25 & 0,95 & 0,94 & 1,00 & 1,01 & 0,95 & 1,00 & 0,79 & 0,78 & 0,85 & 0,74 & 1,00 & 1,07 & 0,46 \\
\hline $\mathrm{Ga} / \mathrm{Al}$ & 2,43 & 2,24 & 2,34 & 2,35 & 2,50 & 2,28 & 2,45 & 2,20 & 2,09 & 2,13 & 2,24 & 2,12 & 2,29 & 2,41 \\
\hline $\mathrm{Eu} / \mathrm{Eu}^{*}$ & 0,60 & 0,83 & 0,74 & 0,81 & 0,70 & 0,76 & 0,75 & 0,88 & 0,79 & 0,84 & 0,85 & 0,82 & 0,69 & 1,41 \\
\hline$[\mathrm{La} / \mathrm{Sm}]_{N}$ & 5,46 & 7,63 & 5,31 & 6,87 & 7,11 & 4,96 & 5,07 & 5,84 & 4,90 & 6,29 & 4,56 & 5,18 & 5,47 & 3,33 \\
\hline$[\mathrm{Gd} / \mathrm{Yb}]_{\mathrm{N}}$ & 1,24 & 1,48 & 1,59 & 1,40 & 1,34 & 1,77 & 1,22 & 1,51 & 1,51 & 1,40 & 1,56 & 1,40 & 1,72 & 1,67 \\
\hline$[\mathrm{La} / \mathrm{Yb}]_{\mathrm{N}}$ & 12,79 & 23,19 & 15,89 & 17,57 & 16,61 & 16,93 & 12,56 & 16,95 & 14,11 & 17,40 & 13,80 & 14,29 & 16,93 & 8,01 \\
\hline
\end{tabular}

te de ambiente tectônico Rb versus $\mathrm{Yb}+\mathrm{Ta}$ (Fig. 7A), posiciona a SIAB no campo das rochas de arco vulcânico. No diagrama que correlaciona $\mathrm{Zr}+\mathrm{Nb}+\mathrm{Ce}+\mathrm{Y}$ versus $\left(\mathrm{Na}_{2} \mathrm{O}+\mathrm{K}_{2} \mathrm{O}\right) / \mathrm{CaO}$, a
SIAB se posiciona no campo dos granitos tipo I não fracionados (Fig. 7C). As médias de alguns elementos compatíveis e incompatíveis mostram relativa homogeneidade, se comparados aos 

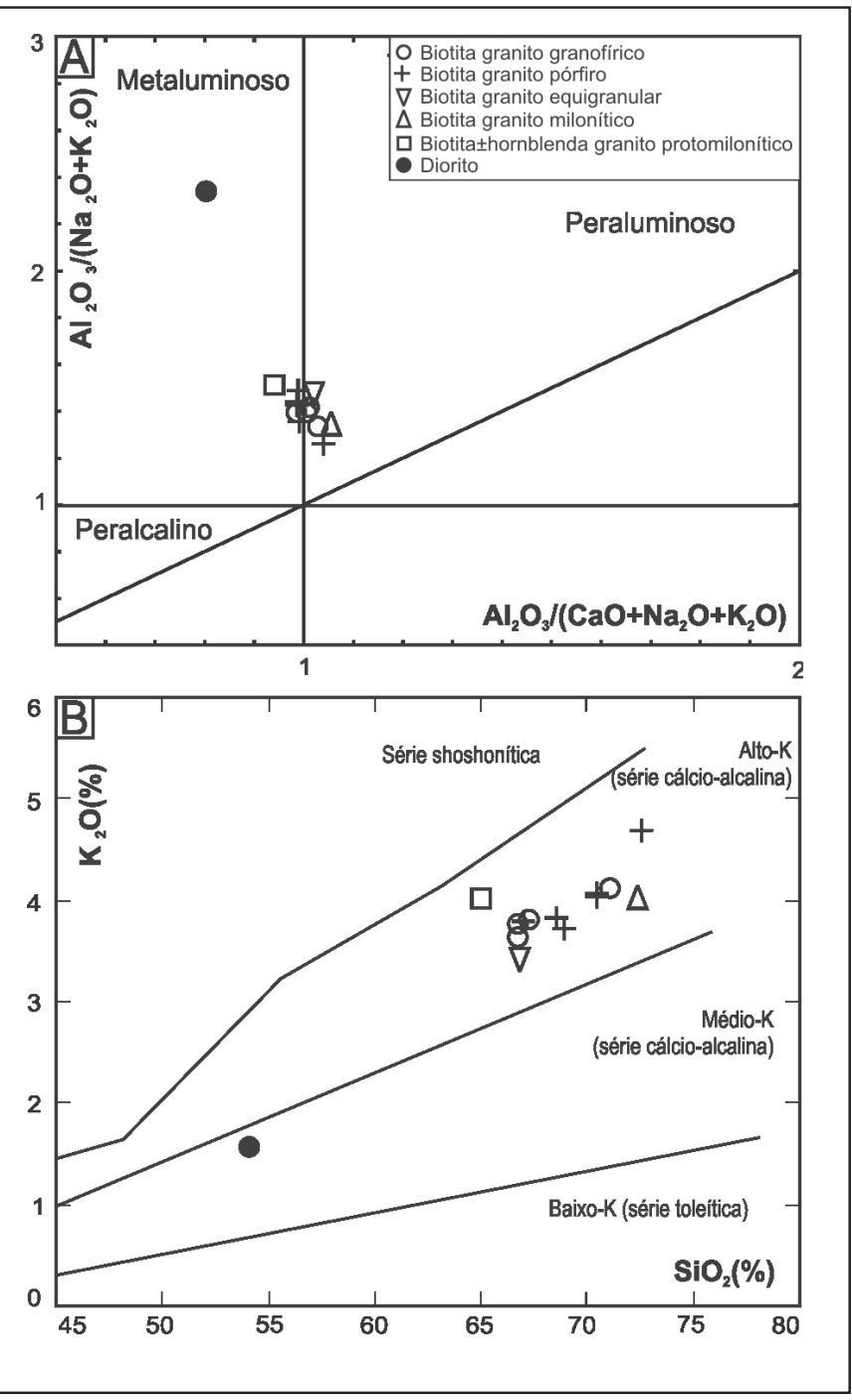

Figura 5. Diagramas de caracterização geoquímica dos granitóides Água Branca. (A) Índice de saturação em alumina (Maniar \& Picolli 1989). (B) Diagrama de correlação entre $\mathrm{SiO}_{2}$ versus $\mathrm{K}_{2} \mathrm{O}$, mostrando o grau de alcalinidade e teor de potássio (Rickwood 1989).

granitos tipo I de Chappell \& White (2001). O enriquecimento exponencial em $\mathrm{Ta}$ e $\mathrm{Nb}$ sugere um trend de maturidade de arco vulcânico com tendência à produção de rochas com características pós-colisionais (Fig. 7C).

GEOCRONOLOGIA Pb-Pb EM ZIRCÃO Neste trabalho são apresentas três idades obtidas pelo método de evaporação de $\mathrm{Pb}$ de monocristais de zircão em duplo filamento para o biotita \pm hornblenda granito protomilonítico, biotita granito pórfiro e biotita granito milonítico da SIAB. Os resultados obtidos excluem cristais que não forneceram sinal de $\mathrm{Pb}$ suficiente para determinação da razão isotópica e cristais que forneceram valores de ${ }^{204} \mathrm{~Pb} /{ }^{206} \mathrm{~Pb}$ superiores a 0,0004 (Tab. 3, Fig. 8).

Biotita \pm hornblenda granito protomilonítico Para obtenção da idade $\mathrm{Pb}-\mathrm{Pb}$ evaporação desse litotipo, foram selecionados inicialmente 21 cristais de zircão, na fração 180-125 $\mu \mathrm{m}$, que exibem cor marrom clara a média, são translúcidos, prismáticos bipiramidais, às vezes subarredondados, curtos (largura:comprimento $=1 / 2$ a $1 / 3$ ), raros zonados, fortemente microfraturados, levemente oxidados e com inclusões opacas e transparentes arredondas e alongadas. A partir deste conjunto de 21 cristais, sete foram analisados e forneceram sinal de $\mathrm{Pb}$ suficientemente intenso para a determinação das razões isotópicas, além de mostrar valores da razão ${ }^{204} \mathrm{~Pb} /{ }^{206} \mathrm{~Pb}$ inferior a 0,0004 . Após a eliminação subjetiva, cinco cristais de zircão foram utilizados para o cálculo da idade média ponderada, revelando um valor de $1898 \pm 3$ Ma, com Unified Standard Deviation (USD) = 1,74. Esse valor foi interpretado como idade de cristalização dos cristais de zircão analisados e, conseqüentemente, do alojamento do biotita \pm hornblenda granito milonítico.

\section{Biotita granito pórfiro}

Onze cristais de zircão forneceram sinal de $\mathrm{Pb}$ suficientemente intenso para a determinação da razão isotópica e valores inferiores 0,0004 , em relação à razão ${ }^{204} \mathrm{~Pb} /{ }^{206} \mathrm{~Pb}$. Esses cristais são de cor marrom média a clara, subtranslúcidos, prismáticos bipiramidais, raros subarredondados, curtos (1/2), zonados, fortemente microfraturados, às vezes fragmentados e contendo inclusões opacas e transparentes subarredondadas e alongadas. Raros cristais apresentam um aspecto leitoso relacionado ao processo de metamitização. Depois de realizada a eliminação subjetiva, seis cristais de zircão foram utilizados para o cálculo da idade média, que revelou o valor de $1895 \pm 3$ Ma (USD = 1,6), interpretado como idade de cristalização do biotita granito pórfiro Água Branca. Cabe ressaltar que o cristal C2101/7 apresentou um desvio na idade de $\pm 31 \mathrm{Ma}$, entretanto, a idade obtida nesse cristal é condizente com a média dos demais cristais.

Biotita granito milonítico Os cristais de zircão selecionados nesse litotipo são de cor marrom clara, subtranslúcidos a translúcidos, prismáticos bipiramidais, curtos (1/4), ocasionalmente com a borda arredondada, zonados, microfraturados, contendo inclusões transparentes e opacas alongadas. Foram reservados onze cristais para análise isotópica, dos quais oito revelaram uma idade média ponderada de $1890 \pm 2 \mathrm{Ma}(\mathrm{USD}=1,62)$, interpretada como a idade mínima de cristalização desse litotipo.

Os cristais C3504/8 e C3504/10 apresentaram idades de $1938 \pm 5$ Ma e $1932 \pm 6$ Ma, que poderiam vir de rochas encaixantes ou terem sido parcialmente rejuvenescidas ao serem imersos no magma granítico Água Branca. Contudo, idades $\mathrm{Pb}-\mathrm{Pb}$ similares $(1,93-1,94 \mathrm{Ga})$ têm sido atribuídas aos charnockitos da Suíte Intrusiva Serra da Prata e a (meta) granitos e gnaisses da Suíte Metamórfica Rio Urubu, ao norte da área de estudo, sul do Estado de Roraima.

DISCUSSÕES As informações que associam a controvertida contemporaneidade entre distintos eventos magmáticos na Província Ventuari-Tapajós ainda são alvo de diversas discussões, sobretudo a partir de modelos de evolução tectônica na Província Aurífera Tapajós, região sobre a qual se concentra um grande número de trabalhos contendo informações geoquímicas, química mineral e geologia isotópica $\mathrm{Pb}-\mathrm{Pb}, \mathrm{U}-\mathrm{Pb}$ e SmNd. Nessa concepção, Santos et al. $(2000,2004)$ descreveram o evento orogênico Tapajós-Parima como sendo formado por diácronos arcos magmáticos cálcio-alcalinos $(2,05-1,88 \mathrm{Ga})$, que pelo processo de fusão parcial em altas temperaturas $\left(>800^{\circ} \mathrm{C}\right)$ e baixa pressão produziram uma assembléia vulcano-plutônica pós-colisional representada pela Suíte Intrusiva Maloquinha e pelo Grupo Iriri, considerados correlatos aos plutono-vulcanismo tipo A da área de estudo (Valério et al. 2006a). Na porção sul dessa província, região do Rio Tapajós, Vasquez et al. (2002) discutiram a mudança do magmatismo cálcio-alcalino orogênico para alcalino pós-orogênico e alertaram para a estreita associação espacial e temporal dos granitóides calcialcalinos e alcalinos nessa região. Esses autores sugeriram também que o magmatismo alcalino poderia ser o estágio tardi-orogênico dos 


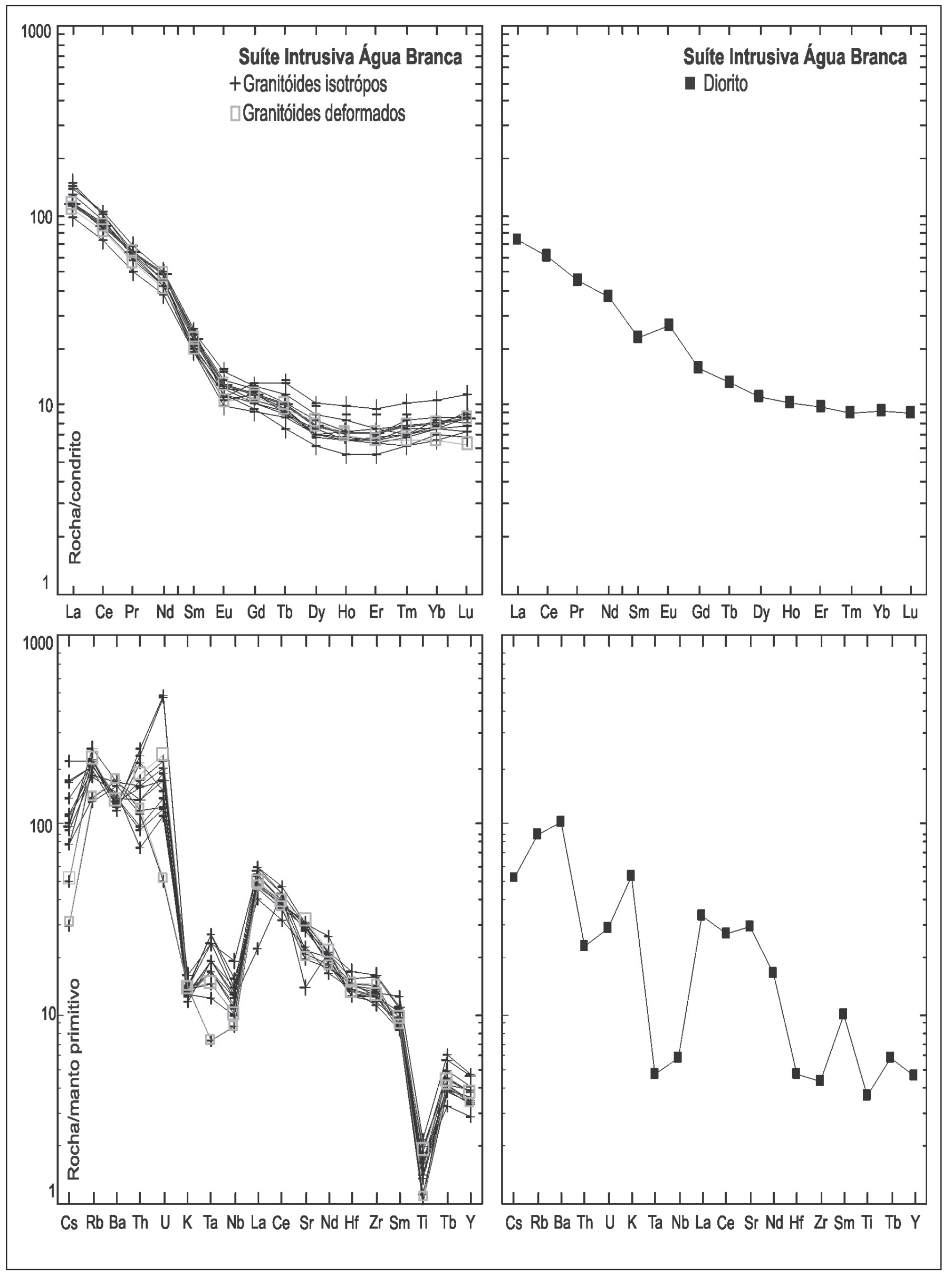

Figura 6. Padrões de distribuição dos ETR e multielementar dos granitóides Água Branca. Valores normalizados de acordo com os condritos de Boynton (1984) e o manto primitivo de McDonough et al. (1992). 

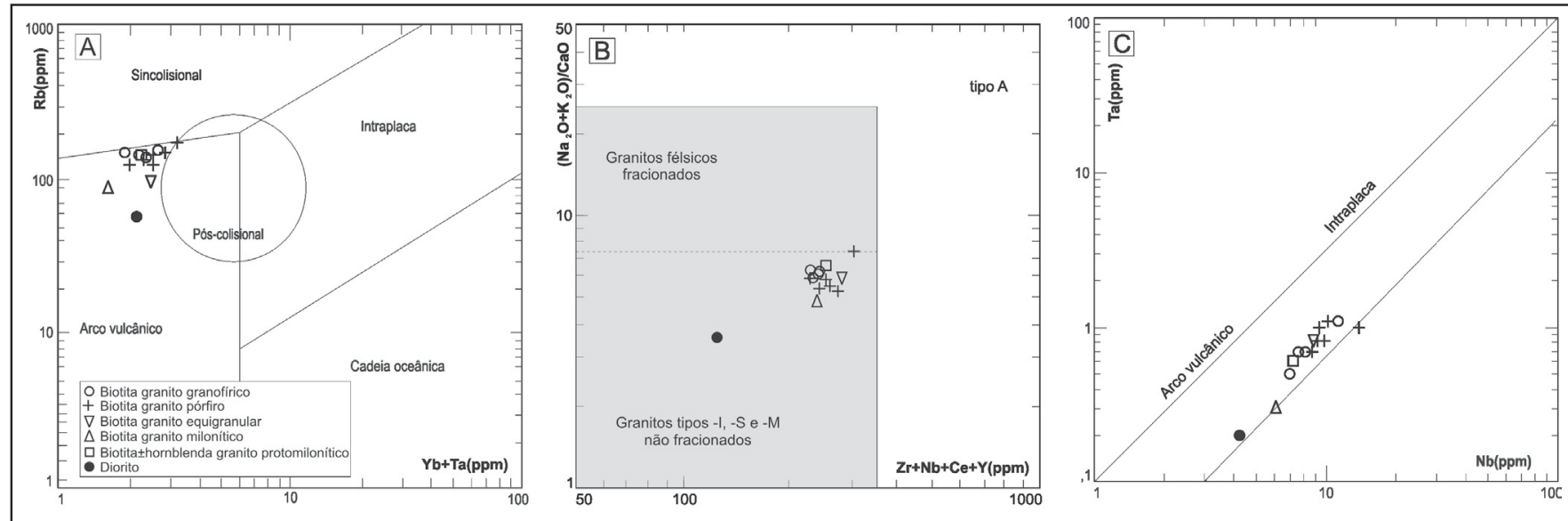

Figura 7. Diagramas discriminantes de ambientes tectônicos. A (Pearce 1996) e B (Harris et al. 1986). (C) Diagrama discriminante de granitóides tipo A, tipo I fracionado e tipo I não fracionado (Whalen et al. 1987).

Tabela 3. Resultados isotópicos obtidos pelo método evaporação de Pb em monocristais de zircão das rochas investigadas. Resultados dos cristais herdados do biotita granito milonitico destacados pelo fundo cinza. $\left({ }^{07} \mathrm{~Pb}{ }^{206} \mathrm{~Pb}\right) \mathrm{c}=$ razões isotópicas corrigidas do Pb comum inicial.

\begin{tabular}{|c|c|c|c|c|c|c|c|c|}
\hline Cristais & $\begin{array}{l}\text { Temp. de } \\
\text { evaporação }\left({ }^{\circ} \mathrm{C}\right)\end{array}$ & $\begin{array}{l}N^{\circ} \text {. de razões } \\
\text { isotópicas }\end{array}$ & ${ }^{204} \mathrm{~Pb} /{ }^{206} \mathrm{~Pb}$ & 2_ & $\left({ }^{207} \mathrm{~Pb} /{ }^{206} \mathrm{~Pb}\right) \mathbf{c}$ & 2_ & Idade (Ma) & 2 \\
\hline \multicolumn{9}{|c|}{ BIOTITA \pm HORNBLENDA GRANITO PROTOMILONÍTICO ÁGUA BRANCA } \\
\hline \multirow[t]{2}{*}{ C6304/1 } & 1500 & 30 & 0,000038 & 4 & 0,11621 & 35 & 1899 & 5 \\
\hline & 1550 & 34 & 0,00005 & 8 & 0,11593 & 38 & 1895 & 6 \\
\hline \multirow[t]{2}{*}{ C6304/2 } & 1500 & 38 & 0,000008 & 4 & 0,1162 & 17 & 1899 & 3 \\
\hline & 1550 & 38 & 0,000025 & 1 & 0,11663 & 34 & 1905 & 5 \\
\hline C6304/5 & 1500 & 28 & 0,000075 & 3 & 0,11596 & 34 & 1895 & 5 \\
\hline C6304/6 & 1450 & 30 & 0,000051 & 1 & 0,11569 & 36 & 1891 & 6 \\
\hline \multirow[t]{2}{*}{ C6304/9 } & 1500 & 34 & 0,000049 & 7 & 0,11626 & 23 & 1900 & 4 \\
\hline & \multicolumn{3}{|c|}{$\sum=\mathbf{2 3 2}$} & & \multicolumn{2}{|c|}{ Média ponderada $=$} & 1898 & \pm 3 \\
\hline \multicolumn{9}{|c|}{ BIOTITA GRANITO PÓRFIRO ÁGUA BRANCA } \\
\hline $\mathrm{C} 2104 / 1$ & 1450 & 38 & 0,000154 & 9 & 0,11557 & 19 & 1889 & 3 \\
\hline \multirow[t]{2}{*}{ C2104/5 } & 1450 & 30 & 0,000048 & 8 & 0,11586 & 56 & 1894 & 9 \\
\hline & 1550 & 30 & 0,000024 & 7 & 0,116 & 2 & 1896 & 3 \\
\hline C2104/7 & 1500 & 8 & 0,000000 & 0 & 0,11563 & 199 & 1890 & 31 \\
\hline C2104/8 & 1500 & 38 & 0,000047 & 3 & 0,11576 & 16 & 1892 & 2 \\
\hline C2104/9 & 1500 & 34 & 0,000015 & 4 & 0,11594 & 15 & 1895 & 2 \\
\hline \multirow{2}{*}{$\mathrm{C} 2104 / 11$} & 1500 & 36 & 0,000090 & 6 & 0,11629 & 18 & 1900 & 3 \\
\hline & & $=214$ & & & Média ponder & da $=$ & 1895 & \pm 3 \\
\hline \multicolumn{9}{|c|}{ BIOTITA GRANITO MILONÍTICO ÁGUA BRANCA } \\
\hline \multirow[t]{2}{*}{ C3504/1 } & 1450 & 24 & 0,000029 & 7 & 0,11586 & 45 & 1894 & 7 \\
\hline & 1480 & 24 & 0,000011 & 9 & 0,11559 & 39 & 1889 & 6 \\
\hline C3504/2 & 1500 & 8 & 0,000136 & 26 & 0,11480 & 156 & 1877 & 24 \\
\hline C3504/5 & 1450 & 32 & 0,000101 & 7 & 0,11543 & 14 & 1887 & 2 \\
\hline C3504/6 & 1450 & 8 & 0,000050 & 8 & 0,11508 & 157 & 1881 & 25 \\
\hline C3504/7 & 1500 & 38 & 0,000099 & 3 & 0,11549 & 19 & 1888 & 3 \\
\hline C3504/8 & 1500 & 32 & 0,000031 & 7 & 0,11879 & 31 & 1938 & 5 \\
\hline \multirow[t]{2}{*}{ C3504/9 } & 1480 & 34 & 0,000016 & 4 & 0,11579 & 18 & 1892 & 3 \\
\hline & 1500 & 30 & 0,000016 & 5 & 0,11586 & 18 & 1894 & 3 \\
\hline C3504/10 & 1450 & 8 & 0,000022 & 1 & 0,11835 & 39 & 1932 & 6 \\
\hline \multirow[t]{2}{*}{ C3504/11 } & 1450 & 36 & 0,000174 & 9 & 0,11527 & 41 & 1884 & 6 \\
\hline & 1480 & 34 & 0,000031 & 7 & 0,11559 & 18 & 1889 & 3 \\
\hline \multirow[t]{2}{*}{ C3504/13 } & 1450 & 6 & 0,000031 & 12 & 0,11549 & 71 & 1888 & 11 \\
\hline & & $=490$ & & & média ponder & da $=$ & 1890 & \pm 2 \\
\hline
\end{tabular}




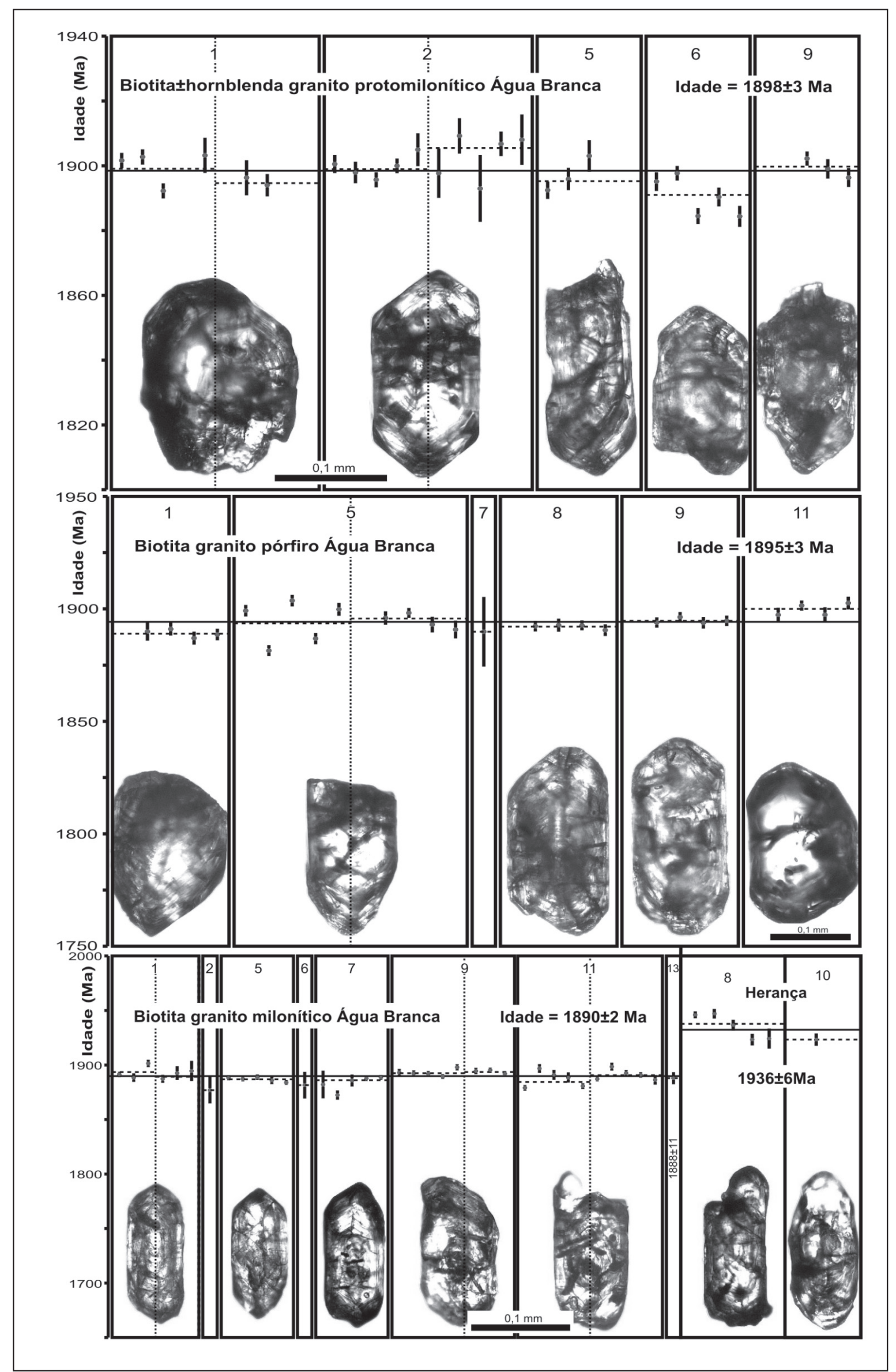

Figura 8. Diagramas Idade (em Y) versus Etapa de Evaporação (em X) dos cristais de zircão empregados no cálculo da idade média ponderada das fácies biotita \pm hornblenda granito protomilonítico, biotita granito pórfiro e biotita granito milonítico da SIAB. Círculo cheio representa blocos de razões isotópicas utilizados no cálculo da idade 


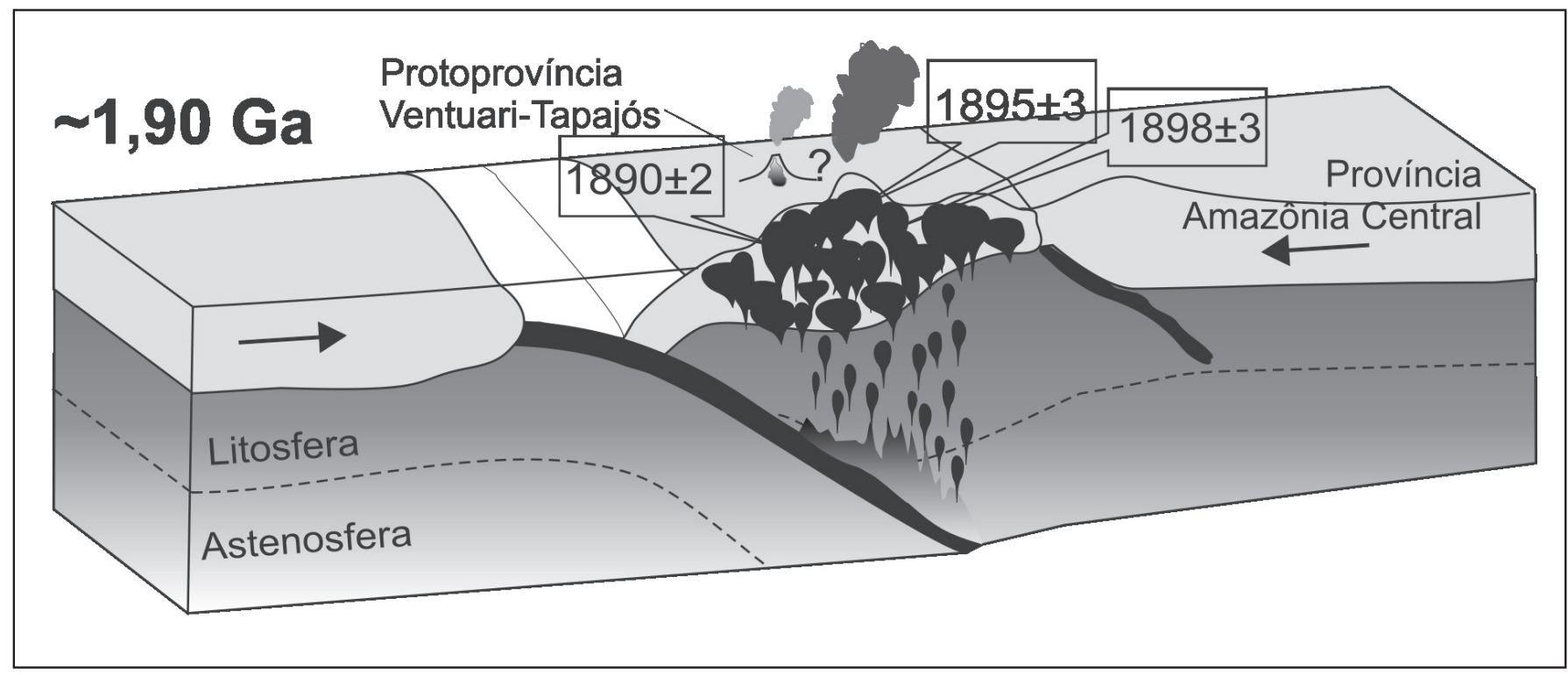

Figura 9. Modelo geotectônico proposto para o alojamento dos granitóides cálcio-alcalinos do extremo sul do Escudo das Guianas, porção norte da Província Ventuari-Tapajós. Fase final de subducção da paleoplaca oceânica sob a Província Amazônia Central, envolvendo os processos finais de colagem e construção da Província Ventuari-Tapajós associado ao magmatismo Água Branca tipo I.

arcos Cuiú-Cuiú ou Tropas.

Segundo Lamarão et al. (2002a, 2002b), a região da Vila Riozinho, localizada na Província Aurífera do Tapajós, se formou durante dois períodos de intensa atividade magmática $(2,0$ 1,97 Ga e 1,89-1,87 Ga), considerando-se duas hipóteses para o segundo período. A primeira gerou rochas alcalinas ainda no processo de subducção e a segunda é associada à ausência de subducção em um período de distensão e magmatismo intraplaca. Lamarão et al. (2005) consideram que os modelos com base em ${ }_{-\mathrm{Nd}}$ indicam que o magma original não foi produzido exclusivamente pela refusão da crosta arqueana e apontam para fontes dominantemente paleoproterozóicas com modificações do magma por interação com a crosta ou por refusão pós- a tardi-orogênica de antigo arco paleoproterozóico com pequena contribuição arqueana.

Na porção norte da Província Ventuari-Tapajós (Estado de Roraima), a CPRM (2000) relaciona os granitóides cálcio-alcalinos da SIAB e os vulcanitos Iricoumé a um estágio tardi- a pós-colisional, seguido, no final do Paleoproterozóico, de estabilidade continental e subseqüentes processos extensionais com desenvolvimento de hemigrábens e intenso magmatismo anorogênico, este último representado pela Suíte Intrusiva Mapuera, acumulações vulcanossedimentares e intrusões de rochas máficas.

CONCLUSÕES A SIAB é constituída na região estudada por granitóides que variam de sienogranitos, passando pelos predominantes monzogranitos até termos dioríticos, os quais exibem arranjos texturais porfiríticos, equigranulares, (proto) miloníticos e granofíricos. A presença de enclaves de diorito, associada aos valores expandidos em $\mathrm{SiO}_{2}, \mathrm{Al}_{2} \mathrm{O}_{3}, \mathrm{Fe}_{2} \mathrm{O}_{3 \text { (total) }}, \mathrm{MgO}, \mathrm{CaO}$ e $\mathrm{Na}_{2} \mathrm{O}+\mathrm{K}_{2} \mathrm{O}$ e relativa homogeneidade na razão $\mathrm{Fe} / \mathrm{Mg}$, sugerem a participação de magmas da Série Granodiorítica Cálcio-alcalina. Os elevados teores em $\mathrm{Ba}, \mathrm{Sr}$ e $\mathrm{Rb} / \mathrm{Zr}$ e baixos valores em $\mathrm{Nb}, \mathrm{Rb}, \mathrm{Ta}, \mathrm{Zr}, \mathrm{Zn}, \mathrm{Y}, \mathrm{K} / \mathrm{Rb}$ e ETRL da SIAB, aliados ao padrão de distribuição dos ETR e em diagramas multielementares, indicam um ambiente sin-colisional com formação de arco magmático, geração de rochas cálcio-alcalinas meta a peraluminosas de médio a alto-K, do tipo I normal ou pouco fracionadas (Valério et al. 2006b). A forte homogeneidade entre o padrão de distri- buição de elementos compatíveis e incompatíveis das rochas da SIAB em relação às rochas de ambiente tipicamente sin- e póscolisionais, contribui com a proposta de um regime colisional envolvendo os processos finais de colagem, subducção de uma paleoplaca oceânica contra o protocráton Amazônico (Província Amazônia Central), subseqüente construção da Província Ventuari-Tapajós (Fig. 9), associados ao magmatismo Água Branca, gerado em torno de 1,89 Ga e que também é considerado correlato ao magmatismo Parauari (Tropas), na porção sul da Província Ventuari-Tapajós (Província Aurífera Tapajós).

As idades muito próximas das rochas deformadas $(1898 \pm 3$ Ma e $1890 \pm 2 \mathrm{Ma})$ e não-deformadas (1895 $\pm 3 \mathrm{Ma}$ ) apontam para um processo heterogêneo, afetando umas rochas e preservando outras. Por outro lado, os aspectos petrográficos e geocronológicos sugerem que a milonitização se deu logo após o alojamento dos corpos Água Branca. Sendo assim, como um processo rúptil que se deu próximo à superfície terrestre, as rochas da região devem ter passado por um soerguimento logo após suas colocações, o que é bem plausível para um ambiente de colisão, vindo fortalecer a hipótese levantada.

Agradecimentos. Ao MCT/CNPq (Processo n $\left.{ }^{\circ} .620181 / 2004\right)$ e CAPES, pelo apoio financeiro e concessão de bolsas de estudo. Aos moradores do ramal do Canoas, por nos receberam de forma hospitaleira. Ao geólogo Mário Sérgio G. Faria, pelas discussões durante os trabalhos de campo. Aos alunos do curso de geologia que participaram das etapas de campo. 


\section{Referências}

Almeida M.E., Macambira M.J.B., Faria M.S.G. 2002. A Granitogênese paleoproterozóica do sul de Roraima. In: SBG, Congresso Brasileiro de Geologia, 41, Anais, 434.

Almeida M.E., Macambira M.J.B. 2003. Aspectos geológicos e litoquímicos dos granitóides cálcio-alcalinos Paleoproterozóicos do sudeste de Roraima. In: SBGq, Congresso Brasileiro de Geoquímica, 9, Anais, 775-778.

Bowden P., Batchelor R.A. Chappell B.W. Didier J. Lameyre J. 1984. Petrological, geochemical and source criteria for the classification of granitic rocks: a discussion. Phis. Ear. Plan. Int., 35:1-11.

Boynton W.V. 1984. Cosmochemistry of the rare earth elements: Meteorite studies. In: P. Henderson (Ed.). Rare earth element geochemistry, Elsevier. p.63-114.

Chappell B.W. \& White A.J.R. 2001. Two contrasting granite types: 25 years later. Aust. Journ. E. Scien., 48:487-488.

CPRM 2000. Programa Levantamentos Geológicos Básicos do Brasil. Caracaraí, Folhas NA.20-Z-B e NA.20-Z-D inteiras e parte das folhas NA.20-Z-A, NA.20-Z-C, NA.21-Y-C e NA.21-Y-A. Estado de Roraima. Escala 1:500.000. Brasília, CD-ROM.

CPRM 2002. Geologia e Recursos Minerais da Amazônia Brasileira, Região Cratônica, Sistema de Informações Geográficas - SIG. Mapa na escala de 1:1.750.000. CD-ROM.

Fraga L.M., Reis N.J. 2002. The calc-alkaline volcano-plutonism in the northern Roraima state, Guiana Shield: Implications for the Uatumã event concept and geotectonic significance. In: Simp. Vulc. Amb. Assoc., 2, Belém (Pa), Anais, 15.

Gaudette H.E., Lafon J.M., Macambira M.J.B., Moura C.A.V., Scheller T. 1998. Comparasion of single filament $\mathrm{Pb}$ evaporation/ionization zircon ages with conventional U-Pb results: exemples from Precambrian of Brazil. Jour. South. Amer. Earth. Scien., 11:351-363.

Harris N.B.W., Pearce J.A., Tindle A.G. 1986. Geochemical characteristics of collision zone magmatism. In: M.P Coward \& A.C. Ries (Eds.). Collision Tectonics. Geological Society Special Publication, 19:67-81.

Hibbard M.J. 1979. Myrmekite as a marker between pre and post aqueous phase saturation in granitic systems. Geol. Soc. Amer. Bul., 90:1047-1062.

Hibbard M.J. 1987. Deformation of incompletely crystallized magma systems: granite gneisses and their tectonic implication. Jour. Geol., 95:543-561.

Hughes C.J. 1982. Igneous Petrology. Elservier Science, New York, Developments in Petrology, 7, 551p.

Köber B. 1987. Single grain evaporation combined with $\mathrm{Pb}$ emitter bedding ${ }^{207} \mathrm{~Pb} / 206 \mathrm{~Pb}$ investigations using thermal ion mass spectrometry and implications to zirconology. Cont. Min. Petr., 96:63-71.

Lamarão C.N. \& Dall'Agnol R. 2002a. Granitóides São Jorge Antigo e São Jorge Jovem: petrografia e geoquímica de magmatismo cálcico-alcalino alto-K paleoproterozóico na Província Aurífera do Tapajós, Cráton Amazônico, In: E.L. Klein, M.L. Vasquez, L.T. RosaCosta (Eds.). Contribuições à Geologia da Amazônia, 3, SBG-NO, Belém, p.53-66.

Lamarão C.N., Dall'Agnol R., Lafon J.-M., Lima E.F., 2002b. Geology, geochemistry and $\mathrm{Pb}-\mathrm{Pb}$ zircon geochronology of the Paleoproterozoic magmatism of Vila Riozinho, Tapajós gold province, Amazonian Craton, Brazil. Prec. Res., 119(1-4):189-223.

Lamarão C.N., Dall'Agnol R., Pimentel M.M. 2005. Nd isotopic composition of Paleoproterozoic volcanic and granitoid rocks of Vila Riozinho: implications for the crustal evolution of the Tapajós Gold Province, Amazon Craton. Jour. S. Amer. Earth Scien. 18:277-292.

Maniar P.D. \& Piccoli P.M. 1989. Tectonic discrimination of granitoids. Geol. Soc. Amer. Bul., 101:635-643.

McDonough W.F., Sun S., Ringwood A.E., Jagoutz E., Hofmann A.W. 1992. Potassium, rubidium, and cesium in the Earth and Moon and the evolution of the mantle of the Earth. Geoc. Cosmoc. Acta, 56(3):1001-1012.

Oliveira M.J.R., Luzardo R., Faria, M.S.G., Pinheiro S.S. 1996a. A Suíte Intrusiva Água Branca no sudeste de Roraima, In: SBG/NO, Simp. Geol. Amaz., 5, Anais, Belém-PA, p.86-89.

Oliveira M.J.R., Almeida M.E., Luzardo, R., Faria M.S.G. 1996b. Litogeoquímica da Suíte Intrusiva Água Branca - SE de Roraima. In: SBG, Congr. Bras. Geol., 39, Anais, Salvador-BA, 2:213-216.

Pearce J.A. 1996. Sources and setting of granitic rocks. Episodes, 19(4):120-125.

Pearce J.A., Harris N., Tindle A. 1984. Trace element discrimination diagrams for the tectonic interpretation of granitic rocks. Jour. Petr., 25:956-983.

Reis N.J., Faria, M.S.G., Fraga, L.M.B., Haddad, R.C. 2000. Orosirian calc-alkaline volcanism and Orocaima event in the northern Amazonian craton, eastern Roraima state, Brazil. Rev. Bras. Geoc., 30(3):380-383.

Reis N.J., Fraga L.M., Faria M.S.G., Almeida M.E. 2003. Geologia do Estado de Roraima, Brasil. In: F. Rossi, L. Jean-Michel, M.L. Vasquez (eds). Geology of France and Surrounding Areas. Ed. brgm. Paris, França. 2-3-4:121-134.

Rickwood P. 1989. Boundary lines within petrologic diagrams which use oxides of major and minor elements. Lithos 22:247-/263.

Santos J.O.S. 1999. New understanding of the Amazon craton gold provinces. New Developments in Economic Geology. Center for Teaching and Research in Strategic Mineral Deposits. University of Western Australia, Perth, 10p.

Santos J.O.S., Hartmann L.A., Gaudette H.E., Groves D.I., Mcnaughton N.J., Fletcher I.R. 2000. A New understand of the provinces of the Amazon Craton based on Integration of field mapping and U$\mathrm{Pb}$ and $\mathrm{Sm}-\mathrm{Nd}$ geochronology. Gond. Res., 3(4): 453-488.

Santos J.O.S, Van Breemen O.B., Groves D.I., Hartmann L.A., Almeida M.E., McNaughton N.J., Fletcher, I.R. 2004. Timing and evolution of multiple Paleoproterozoic magmatic arcs in the Tapajós Domain, Amazon Craton: constraints from SHRIMP and TIMS zircon, baddeleyite and titanite U-Pb geochronology. Prec. Res., 131:73-109.

Stacey J.S. \& Kramers J.D. 1975. Aproximation of terrestrial lead isotope evolution by a two stage model. Earth Plan. Sci. Lett., 26:207-221.

Streckeisen A. 1976. To each plutonic rock its proper name. Earth Scien. Rev., 12:1-33.

Tassinari C.C.G. \& Macambira M.J.B. 2004. A evolução tectônica do Cráton Amazônico. In: V. Mantesso-Neto, A. Bartorelli, C. Dal Ré Carneiro, B.B. Brito-Neves. Geologia do Continente Sul-Americano: evolução da obra de Fernando Flávio Marques de Almeida. Beca, São Paulo, p.471-485.

Valério C.S., Souza V.S., Macambira M.J.B, Galarza M.A. 2006a. Aspectos geoquímicos e idade $\mathrm{Pb}-\mathrm{Pb}$ da borda sudeste do batólito São Gabriel, Município de Presidente Figueiredo (AM), Escudo das Guianas: Implicações tectônicas. In: SBG/NO, Simp. Geol. Amaz., 9.

Valério C.S., Souza V.S., Macambira M.J.B. 2006b. Granitóides calcialcalinos do extremo sul do Escudo das Guianas, Município de Presidente Figueiredo (AM): petrografia e geoquímica da Suíte Intrusiva Água Branca. In: SBG/NO, Simp. Geol. Amaz., 9.

Vasquez M.L., Ricci P.S.F., Klein E.L. 2002. Granitóides pós-colisionais da porção leste da Província Tapajós. In: SBG, Contribuições à Geologia da Amazônia, 3, Belém, p.67-83.

Whalen J.B., Currie K.I., Chappell B.W. 1987. A-type granites: geochemical characteristics, discrimination and petrogenesis. Contr. Miner. Petr., 95:407-419.

Manuscrito AE017

Revisão aceita em 17 de agosto de 2006 